\title{
(C) OPEN ACCESS \\ Critical orientations for humanising health sciences education in South Africa
}

\author{
Michelle Pentecost, ${ }^{1,2}$ Berna Gerber, ${ }^{3}$ Megan Wainwright, ${ }^{4}$ Thomas Cousins ${ }^{5,6}$
}

'Department of Global Health and Social Medicine, King's

College London, London, UK

${ }^{2}$ School of African and Gender

Studies, Anthropology and

Linguistics, University of Cape

Town, Cape Town, South Africa

${ }^{3}$ Division of Speech, Language and Hearing Therapy, Faculty of Medicine and Health Sciences, University of Stellenbosch, Cape Town, South Africa

${ }^{4}$ Division of Social and

Behavioural Sciences, School of Public Health and Family Medicine, University of Cape Town, Cape Town, South Africa Institute of Social and Cultural Anthropology, University of Oxford, Oxford, UK

${ }^{6}$ Department of Sociology and Anthropology, University of Stellenbosch, Stellenbosch, South Africa

\section{Correspondence to} Dr Michelle Pentecost Department of Global Health and Social Medicine, King's College London, London WC2R 2LS, UK;

michelle.pentecost@kcl.ac.uk

Accepted 24 July 2018
Check for updates

(c) Author(s) (or their employer(s)) 2018. Re-use permitted under CC BY-NC. No commercial re-use. See rights and permissions. Published by BMJ.

To cite: Pentecost $\mathrm{M}$, Gerber B, Wainwright M, et al. Med Humanit 2018:44:221-229.

\section{ABSTRACT}

In this article, the authors make a case for the 'humanisation' and 'decolonisation' of health sciences curricula in South Africa, using integration as a guiding framework. Integration refers to an education that is built on a consolidated conceptual framework that includes and equally values the natural or biomedical sciences as well as the humanities, arts and social sciences, respecting that all of this knowledge has value for the practice of healthcare. An integrated curriculum goes beyond add-on or elective courses in the humanities and social sciences. It is a curriculum that includes previously marginalised sources of knowledge (challenging knowledge hierarchies and decolonising curricula); addresses an appropriate intellectual self-image in health sciences education (challenging the image of the health professional); promotes understanding of history and social context, centring issues of inclusion, access and social justice (cultivating a social ethic) and finally, focuses on care and relatedness as an essential aspect of clinical work (embedding relatedness in practice). The article offers a brief historical overview of challenges in health and health sciences education in South Africa since 1994, followed by a discussion of contemporary developments in critical health sciences pedagogies and the medical and health humanities in South Africa. It then draws on examples from South Africa to outline how these four critical orientations or competencies might be applied in practice, to educate health professionals that can meet the challenges of health and healthcare in contemporary South Africa.

\section{INTRODUCTION}

The dehumanisation of healthcare has been defined as the loss of respect, empathy and integrity in the clinician-patient relationship. ${ }^{1}$ The philosophical underpinnings of biomedical systems cast the body as a mechanical, universal object, which is ahistorical and without culture or politics, ${ }^{2}$ and a lack of humanism in healthcare is seen as the inevitable outcome of a system that focuses on bodies, disease and technology. ${ }^{3}$ As elsewhere in the world, South Africa suffers a crisis in healthcare in relation to clinicians developing practices that appear to lack empathy and devalue the patient's experience and perspective. ${ }^{4-7}$ For South Africa and other postcolonies, modern biomedicine has been indelibly shaped by colonial histories, reflected in its infrastructures, bureaucracies and pedagogies. The legacies of apartheid and the challenges of creating an integrated national health service in the postapartheid $\mathrm{era}^{8}$ have profoundly influenced what it means to deliver humanised healthcare in South Africa. In this article, we offer four critical orientations that make up an integrated framework for humanising and decolonising health sciences education in South Africa.

What it might mean to humanise is a debate that has raged in the humanities, especially in the global North, for several decades. We do not aim to settle this debate here, suffice to say that even as cultural theorists have arrived at formulations of a 'posthuman' or 'more-than-human' theory of life, postcolonial scholars have cautioned that Africans are still forced to assert their claim to a full humanity in the face of actually existing violence and structural forms of oppression that continue to deny their inclusion..$^{9-11}$ For health sciences pedagogy in South Africa, humanising education is thus part of a broader collective effort in South African tertiary education that prioritises transformation, equity and equal participation in the name of social justice.

For many scholars, decolonising education is an integral part of this project. Attempts to 'decolonise' education are not new and have varied histories. ${ }^{12}$ wa Thiong'o offers a useful definition: as a means of recentring one's perspective without necessarily having to reject other streams of thought. ${ }^{13}$ South African educationalists have characterised decolonised education as 'higher education for the public good. ${ }^{14}$ As these scholars have noted, it is imperative that attempts to decolonise curricula are borne from local context and experience. In the South, 'conditions are different (from the North), and the particular experience of struggle against injustice and for equality and human flourishing takes on forms which may differ in terms of both content and intensity, from forms (elsewhere)'. ${ }^{14}$ 'The South' in this configuration is not a straightforward geographical or analytical category, but a descriptor that acknowledges new inequalities and flows of knowledge. ${ }^{12} 15$

Thus, while humanising and decolonising health sciences education are distinct ideas, in this article, we seek to think with decolonising efforts as part of what humanisation might mean in the specific social, political and historical context of South Africa. Following Mbembe, we adopt an openended orientation to what it might mean to decolonise education in South Africa in the 21st century, as knowledge 'futures' and 'pasts' are revised, and as the university itself is contested. ${ }^{12}$

We suggest that attempts to humanise or decolonise the health sciences in South Africa need to focus on the 'what', and on the 'how' if we are to make important gains in improving health sciences education and training. While important foundations have been laid by efforts to bridge biomedicine with the humanities and social sciences to humanise 
health sciences education, we argue that a transformed health sciences curriculum will have to go beyond add-on or elective courses in the humanities and social sciences. As Subreenduth has also argued, decolonising pedagogy will require more than 'case studies and reading about poverty, difference and diversity'. ${ }^{16}$

We make a case for integration as a potentially powerful guiding framework for decolonising and humanising health sciences education. By integration we mean an education that is built on a consolidated conceptual framework that includes and equally values the natural or biomedical sciences as well as the humanities, arts and social sciences, respecting that all of this knowledge has value for the practice of healthcare. ${ }^{17} 18$ We propose the integration of a consistent framework across teaching and learning of all subjects and rotations in a health sciences curriculum, which promotes four competencies: (1) the integration of previously marginalised sources of knowledge (challenging knowledge hierarchies and decolonising curricula); (2) the integration of an appropriate intellectual self-image in health sciences education (challenging the image of the health professional); (3) an integrated understanding of history and social context, centring issues of inclusion, access and social justice (cultivating a social ethic) and (4) an integrated focus on care and relatedness as an essential aspect of clinical work (embedding relatedness in practice).

The article proceeds as follows: we offer a brief historical overview of health sciences education in South Africa since 1994, followed by a discussion of contemporary developments in critical health sciences pedagogies and the medical and health humanities in South Africa, on which our work builds. We then outline the four critical orientations that make up the fabric of our integrative framework and offer examples of what integration might look like in practice. It is important to note that the ideas put forward in this article are drawn from the combined experiences of the four authors in training and educating health sciences students in South Africa. Of the four authors, two were clinically trained in South Africa: one is trained in philosophy and three in anthropology. The interdisciplinary/transdisciplinary perspectives offered here draw on scholarship in philosophy, medical anthropology, education and bioethics, as well as our personal experiences of learning, working and teaching in the health sciences in South Africa.

\section{HEALTH SCIENCES EDUCATION IN SOUTH AFRICA: PAST AND PRESENT}

Like biomedicine, higher education in South Africa has been deeply influenced by the country's colonial and apartheid past. The social, political and economic inequalities based on race, class and gender of these regimes led to systemic inclusion and marginalisation of certain social classes and groups. Apartheid ideology and planning created tertiary education institutions that were assigned to different 'race' groups $s^{i}$ that were highly unequal in terms of privilege, funding and status. ${ }^{19}$ Of the eight medical schools that existed before the first democratic election in 1994, only three admitted non-white students. For three out of the five 'white universities', Afrikaans, the official state language

\footnotetext{
i The Population Registration Act of 1950 decreed that each citizen should carry an identity document that recorded his race as either 'white', 'coloured' or 'native'; this was later modified to divide the population into four groups: 'African', 'Indian', 'coloured' and 'white'. ${ }^{103}$ In democratic South Africa, the national census describes the population as 'black African', 'white', 'coloured' and 'Indian'. We use the terms as used in the census as these are consistent with common usage, but this does not imply our acceptance of racial attributes of any sort.
}

during apartheid, was the sole medium of instruction..$^{20}$ In the pre-1994 period, higher education was thus highly skewed by race, language and gender. People of colour, especially women, faced huge obstacles to entering higher education. ${ }^{19}$

Nearly 25 years after the end of apartheid, South Africa remains one of the most unequal societies in the world, a disparity reflected in the country's disease burden. South Africa is described as having a quadruple burden of disease, with high rates of HIV/AIDS and tuberculosis, high maternal and child mortality and malnutrition, non-communicable disease rates rising in rural and urban areas as well as high levels of violence and injuries. ${ }^{8}$ The inequality that characterises South Africa is dramatically visible in its healthcare system: the public health sector provides services to approximately $84 \%$ of the country's population, while only $30 \%$ of the country's doctors work in this sector. ${ }^{21}$ Public healthcare facilities are in a state of crisis due to underfunding and mismanagement. ${ }^{21}{ }^{22}$ Working conditions and salaries in the public health sector do not compare favourably with the private health system, making it difficult to attract and retain staff. ${ }^{20}$ However, since the advent of democracy, there have been extensive changes in the higher education sector to address the development needs of the country, including enrolling higher numbers of health sciences students; shifting teaching and training from tertiary-level academic hospitals to primary healthcare settings and according to primary healthcare principles and implementing compulsory community service for health professions graduates in remote locations to address inequalities between rural and urban services. ${ }^{20}$ Transformation in student profiles has occurred to some degree: women and students of colour now constitute the majority in medical classrooms ${ }^{21}$ but students from rural, poor and working class backgrounds still have limited access. ${ }^{19}{ }^{20}$ Transformation in academic staff profiles has followed a slower pace. ${ }^{23}$

After 1994 and the transition to democracy, curricular reform focused on producing practitioners 'fit-for-service' in the postapartheid era. ${ }^{23}$ Medical curricula were revised in the early 2000 s to reflect the aims of the National Health Plan, which focused on a Primary Healthcare approach. The '5 star doctor' was offered as 'the best fit', whose desired attributes included the following: 'provides integrative, curative, preventive and rehabilitative care; works in teams; uses technology optimally; balances community/individual needs and promotes healthy lifestyles.. ${ }^{24}$ More recently, Mash et al have defined the South African primary care clinician as a practitioner that, apart from being 'clinically competent', is also 'a change agent, critical thinker, capability builder, collaborator and community advocate'. ${ }^{25}$ These comprise the 'graduate attributes' that universities aspire to-that graduates should in addition to their technical training 'be agents of social good'. ${ }^{26}$ The doctor as 'change agent' builds on a long history of political critique and activism in some health sciences faculties during apartheid. ${ }^{2027}$

Contemporary efforts to foster such attributes have centred on bridging the health sciences and humanities and social sciences in tertiary education in South Africa. Programmes developed in the last 5 years include 'medical humanities' (University of the Witwatersrand); 'medicine and the arts' and 'critical health social sciences' (University of Cape Town) and 'transdisciplinary health and development studies', and 'health and society' (Stellenbosch University). In 2012, the first research group in medical humanities in Africa was established at the University of the Witwatersrand and it currently offers two postgraduate courses in medical humanities. In 2014, the University of Cape Town (UCT) launched a Massive Open Online Course in Medicine and the Arts co-convened by a family physician and medical 
anthropologist, ${ }^{28}$ and appointed the first lecturer in medical humanities in South Africa. Historian Carla Tsampiras and her colleagues have grown the 'Critical Health Humanities' for health sciences students in the second and third years of the UCT Medicine programme and the third year Physiotherapy programme. In the same year, the Division of Social and Behavioural Science, shaped by the disciplinary training in critical medical anthropology and epidemiology of core members of staff, was founded in UCT's School of Public Health and Family Medicine. At Stellenbosch University, the Unit for Research on Health \& Society has been complemented by MPhil and Postgraduate Diploma programmes jointly convened by the Departments of Sociology and Social Anthropology, and Global Health since 2016. Collectively, these programmes provide opportunities for interdisciplinary studies mostly at a postgraduate level. Although each has forged a different approach to bridging the social sciences and humanities and the health sciences, all founders of these programmes are members of the burgeoning Medical and Health Humanities Network Africa ${ }^{\text {ii }}$. There is thus a productive base on which to build integrative approaches to health sciences education in the South African context.

Concerns about transformation and the decolonisation of curricula, pedagogies, institutional cultures and physical environments of higher education came to the fore during countrywide student protests in 2015. The student protests included significant action by health sciences students concerned with how to concretize debates on access, justice and transformation of the healthcare system as well as health professions education. Students at historically white universities were especially vocal about a need for curriculum change that would 'reflect the lived experiences of African people, including recognition of their scholarly work which is often on the periphery or taught as additional modules'. ${ }^{29}$ Health sciences faculties across the country have had to grapple with questions of tone, respect and the status of knowledge that originates in local worldviews and healing traditions. For example, in response to student protests, UCT health sciences faculty convened transformation forums in 2016 for staff and students, which led to the establishment of the Curriculum Change Working Group and the Undergraduate Oversight Task Team. ${ }^{30}$ This facilitated a process of debate, exchange and institutional recognition of students' experiences of exclusion and institutional racism.

There remains a clear need for curricular reform in health sciences education in South Africa that attends to the complexities of health and healthcare in this context while also dismantling persistent epistemological hierarchies that devalue local knowledge and experience. It is our contention that the addition of humanities-inspired courses cannot in itself transform or 'decolonise' medical education-and certainly not in the way being demanded by health sciences students in South Africa. We turn now to consider a broad definition of competence that might inform pedagogy and epistemology in the South African context, given the centrality of issues of competence and 'epistemological access' in South African higher education. ${ }^{14}$

\section{CRITICAL HEALTH PEDAGOGIES: THE QUEST FOR COMPETENCE REVISITED}

Competence emerged as a key framework for medicine and medical education in the USA in the late 20 th century. ${ }^{31}$ As part of that story, cultural competence emerged as a desirable

\footnotetext{
${ }^{\text {ii }}$ See https://medicalandhealthhumanitiesafrica.wordpress.com.
}

attribute in the 1970s. While the impetus to train culturally sensitive clinicians may have had admirable intentions, the cultural competence approach received much criticism for its emphasis on ethnic and racial identifiers as markers of 'culture', with implications for diagnosis and treatment. ${ }^{3233}$

More recently, the 2014 Lancet Commission on Culture and Health has called for a reconsideration of competence 'across all cultures and systems of care'. ${ }^{33}$ The Commissioners draw on an expanded definition of cultural competence that includes awareness of one's own knowledge and value systems, including insight into medicine as its own culture ${ }^{34}$; an understanding that culture includes the domains of politics, economics, law, ethics and morality for both practitioner and patient; understanding that health and health systems exist in a globally interconnected framework and focusing on relationship, meaning-making and care: 'cultural competence is caring competence'. ${ }^{33}$ The Commission also calls for close attention to the relationship between culture, health inequalities and healthcare delivery-what is elsewhere termed structural competency. ${ }^{35}$ The concept of structural competency has emerged in recent years as a response to the perceived limits of the cultural competency model, and focuses on training clinicians to think beyond the individual to contextualise health problems in their wider structural configurations, including markets, institutions, health systems and political-economic environments. ${ }^{35}$

We draw on Brazilian theorist Freire's notion of critical pedagogy $^{36}$ and these recent approaches to competence to outline four potential competences or critical orientations: (1) a critical approach to knowledge production that challenges knowledge bierarchies; (2) the development of an appropriate intellectual self-image among health professions educators and graduates that challenges the image of the health professional; (3) a sophisticated understanding of political economy and the structural determinants of health that cultivates a social ethic and (4) the ability to engage reflexively as a caregiver and to value relationship, relatedness and experience, embedding relatedness in practice.

\section{Challenging knowledge hierarchies}

The student protests in South African tertiary education since 2015 reignited debates on what it might mean to 'decolonise' education. ${ }^{37}{ }^{38}$ Students' cries for decolonisation in South Africa were about fees, land, inequality, gender, language, institutional culture and racism, but they were also about knowledgewho produces it, where and how and how relevant it is to the context where it is applied. ${ }^{29}{ }^{39-41}$ Students expressed a desire for curricula that 'speak from the South'. In addition to institutional change, ideas about what constitutes a decolonised epistemology included historicising the production of knowledge outside Euro-America; more explicitly recognising other forms of knowledge as reflected in the ethnographic archive and in contemporary practice and grounding claims to knowledge in a philosophical concept that takes histories of slavery and colonialism as critical to knowledge production, including in science and medicine, across metropolitan and colonial networks. Students and scholars across South African universities invoked a range of literature to support this idea, particularly embracing the black consciousness writings of Fanon and Biko. ${ }^{42} 43$

Yet what it means to 'decolonise' health sciences curricula presents fraught paradoxes that require careful negotiation. As physician-anthropologist Dewachi has noted in a Middle Eastern context, the task of pushing positivist boundaries in health sciences education in a non-Western setting produces a 
'double marginality' that engenders its own anxieties. ${ }^{44}$ Dewachi explains that the social science approaches so often deployed to 'humanise' medical curricula, such as medical anthropology, often have as complex a history of engagement with the postcolony as biomedicine itself. As in Dewachi's experience, the contemporary 'dilemmas of engagement' that such histories produce are equally pronounced in the South African context.

Indeed, many of the scholars in the emerging 'medical humanities' community in southern Africa, including this article's authors, would be considered white and middle-class. How might these categories and subject positions shape the perspectives advanced here and condition the force of our claims? Apart from a shared concern to 'speak from the South' in spite of these positionalities, one possible point of common concern lies in the desire to engage with the traumatic history of colonialism and a contemporary social system that continues to reproduce inequality.

Another is the devaluation of personal and experiential forms of knowledge in current evidence-based hierarchies of knowledge. When student protesters cite the exclusion of lived-experiential knowledge, such as knowledge from one's ancestors or indigenous modes of diagnosis, they express a concern that what cannot be measured by the scientific method is simply omitted, dismissed or discredited. The dismissal of personal voice here has parallels with the prioritisation of quantitative rather than qualitative knowledge in biomedical research. Biomedicine's 'evidence pyramid' omits qualitative research entirely. ${ }^{45}$ Wainwright and Macnaughton highlight the absurdity of including 'patient representatives' on guideline committees when patientvoices are silenced through exclusion of qualitative evidence from the realm of 'relevant' evidence for guidelines. ${ }^{46}$ While this approach is largely to do with how clinical questions are framed, the inherently poor status of qualitative research implicit in these hierarchies increases the risk that questions that cannot be answered through quantitative means may not be asked at all. If qualitative questions are not asked, this excludes from the realm of 'relevant knowledge' an enormous body of literature on patient voices including the experience of illness, treatment and relationships with healthcare systems and providers from cross-cultural perspectives.

There are thus two parallel issues at stake for challenging knowledge hierarchies and decolonising curricula: the marginalisation of lived-experiential knowledge, and the marginalisation of knowledge produced in the South, including but not limited to, the work of black scholars. In both cases, there is a privileging of science and knowledge from the 'North'. This often produces a disconnect between what South African students learn and what they experience in practice. For example, Pillay and Kathard reflect on how their training in Audiology and Speech-Language Therapy was at odds with their lived-experience as black South Africans as they had 'essentially been educated to best serve a white, middle-class, colonial-rooted world'. ${ }^{47}$ They argue for developing and valuing local ways of doing professional practice and call for 'critical-emancipatory ways of knowing' that 'will generate cognitive freedoms, innovations and creativityaway from traditional, empirically oriented and/or technically oriented, content-driven knowledge processes'. Similarly, the work by Kaminer et al critiques the transposing of existing models of post-traumatic stress disorder from the global North to a South African context where trauma for many is continuous as a result of gang and community violence. ${ }^{48}$

There is an explicit link between the marginalisation of voices from the South and the marginalisation of qualitative modes of knowledge production. As Daniels et al argue, for researchers in Africa the 'methodological gatekeeping within mainstream publishing privilege[s] certain voices in global health over others, and in so doing, in effect silenc(es) many researchers in low-income and middle-income countries'. They highlight that some of the most pressing questions that need answering to improve health equity in their countries are answerable through social science, particularly qualitative research. ${ }^{49} 50$ One way of inverting hierarchies is therefore methodological: as Chilisa has argued in her work on decolonised transdisciplinary research approaches, 'methodologies rooted in African philosophies, worldviews and history, bring to the academic discourse alternative ways of conducting research.. ${ }^{51}$

Qualitative research is sufficiently broad and flexible to encourage innovation and adaptation to context for both participants and researchers. Patient voice and knowledge drawn from 'lived-experience' is captured particularly well by qualitative approaches, and there is increasing recognition of the benefit of systematic reviews of qualitative research ${ }^{52}$ for decision-making. For example, qualitative evidence syntheses have brought to the fore that the efficacy of treatment is not defined solely by its pharmacological actions. A treatment found to be efficacious in the controlled trial could have little effect on human health if the treatment is not acceptable or feasible in a given context or if implementation issues have not been taken into account. ${ }^{52}$ South African scholars have played a key role at the global level in developing methodologies and guidelines for qualitative evidence synthesis. ${ }^{53} 54$ iiii Privileging qualitative approaches and the forms of knowledge they make visible should be reflected in our approaches to reforming curricula in health sciences in South Africa while also incorporating a critical perspective on these very processes. ${ }^{55}$ For example, Chambers et al reflect on the tensions they experienced as Indigenous and African-descent scholars applying the method of a scoping review to decolonising methodologies. ${ }^{56}$ The importance of such critical perspectives for students' education cannot be overstated in a move to an integrated model of health sciences education that responds to students' demands for decolonised education.

There are useful examples of courses that embrace the notion that there are both multiple questions and multiple ways of knowing. For instance, the elective course Medicine and the Arts at UCT was designed around guest lecturers from social science, humanities, science and artistic backgrounds coming together to teach a variety of perspectives on a single topic. Another attempt at integration is the Critical Health Humanities at UCT. It is a core part of the medical curriculum and uses fictional 'cases' for each system under discussion, allowing each of the 17 departments that teach on the course to add prompts that guide students to identify particular learning objectives using problem-based learning, thus aiming for a 'holistic biopsychosocial' synthesis.

Approaching topics from multiple perspectives and ways of knowing, all on par with one another, is an important model, and might be most readily achieved by the hiring of more interdisciplinary or transdisciplinarily trained lecturers in health sciences faculties. In this model, one can imagine a rotation in psychiatry including the study of psychiatrist Aina's analysis of the portrayal of mental illness in West African film and implications for stigmatisation of the psychiatrically ill, ${ }^{57}$ or a palliative care rotation including a reading of first-hand accounts of exploitation and care work in South Africa. ${ }^{58}$ In this case, integration is signified

\footnotetext{
iii As part of the Global Evidence Summit held in Cape Town in 2017, UCT and the Medical Research Council joined forces to provide a three-day training on qualitative evidence synthesis.
} 
by the presence of a realm of knowledges that are not defined against each other along a hierarchy, but along the kinds of questions they can answer.

Another alternative for integrating rather than adding social sciences and humanities approaches to already stretched curricula is to focus on research methods training. Wainwright and Colvin propose that training in qualitative research become a core component of health sciences curricula. Students undertake their own research to experientially increase their qualitative literacy. Using small group teaching, interdisciplinary instructors create a dynamic learning environment where the students' research drives the introduction of social science and humanities knowledge, theory and methods Wainwright and Colvin, unpublished data, 2018). Such an approach, combined alongside greater integration of the qualitative evidence base across the curriculum, would constitute a significant move towards shifting knowledge hierarchies in health sciences education.

\section{Challenging the image of the health professional}

The second critical orientation we pose is a well-developed and appropriate sense of professional identity among healthcare educators and graduates. The concern that clinicians have become 'too scientific' and 'less caring' is a longstanding one. ${ }^{59}$ The significant cultural, moral and ethical impacts of biotechnological advances on an increasingly globalised medical imaginary in recent decades has brought with it important shifts in understandings of 'best practice'. ${ }^{60}$ As elsewhere, 'critical thinking' is frequently listed as a core competency for medical students, yet this is not well defined, and is not explicitly addressed by curricula. ${ }^{61}$ In the US setting, Kleinman and Hanna argue that 'the professional practice of medicine, the proliferation of medical technology and the exigencies of the healthcare industry have been pushing clinicians even further from the intimate engagement with another's suffering that is inherent in the labour of taking care of another human'. ${ }^{4}$

The humanities and social sciences have much to offer for reflecting on and developing an appropriate intellectual selfimage as a health professional and not just as a scientist. ${ }^{62} 63$ Approaches from science-and-technology studies, which seek to understand the social production of scientific knowledge, provide a useful theoretical framework here,${ }^{64}$ particularly on the production of the biomedical body. ${ }^{65}$ Biomedical science is an important foundation of biomedicine, but should be understood as both a particular epistemology and as a set of norms and values that shape the cultural contexts of scientific discovery and application. How can we teach health professionals to think of themselves not primarily as scientists, but as healers with scientific knowledge and specialised skills, including narrative reasoning ability?

Healthcare, and especially medicine, is commonly thought of, both by its practitioners and the general public, to be a natural science, and 'natural science' is mostly conceived of in outdated logical positivist terms. ${ }^{66}{ }^{67}$ Scholars and clinicians have argued that, when critically examined, medicine is not a natural science. Doctors use a different reasoning style to natural scientists. Instead of thinking deductively, doctors think in an interpretive, dialogical and narrative manner when they treat patients. ${ }^{1768} 69$ Medicine is better described as a practice that draws on biomedical facts, and on clinical experience and knowledge of the many ways in which patients differ from one another, both in terms of their biologies and their life stories. ${ }^{17}$ In order to know and effectively treat individual patients, health professionals need to learn to listen and speak to them. Apart from the eminent sensibility of adopting an appropriate 'intellectual self-image', it is vital for good relationships and communication between practitioners and their patients and ultimately for good quality healthcare. When clinicians think of themselves as natural scientists and consider their primary duty as consisting of the physical care of physiological disorders, they neglect clinician-patient communication and the psychosocial realities and needs of their patients-both essential components of humanised and contextually responsive healthcare. ${ }^{70}$

Another more obvious complication to clinician-patient communication in multilingual and multicultural contexts like South Africa is that patients are often treated in a language other than their own first language, because health professionals do not speak their patients' mother tongues. ${ }^{71}$ As Luckett argues, '[t]he hegemony of colonial languages, especially English, as the global language of business and the internet continues in post-colonial states, despite constitutional claims to the contrary'. ${ }^{72}$ This means that the teaching and practice of health sciences takes place predominantly in English, with consequences for students and patients alike.

The cultivation of the image of clinician as healer needs to be integrated into the curriculum: it should inform classwork and study materials of both basic and clinical sciences and be modelled at the bedside. All those involved in the training of future health professionals should cultivate and model an appropriate self-image. One step towards producing graduates with a critical awareness of the nature of their profession and a clinical skillset that matches it would be to 'train the trainers' in appropriate instruction and role modelling. An example is a faculty development initiative, informed by the field of philosophy, which will be introduced at Stellenbosch University by Gerber in 2019 in the form of a short course to clinical educators. ${ }^{70}$ The broad aims of the course are to foster an appreciation of the nature and identity of clinical medicine as a particular professional discipline and praxis; and to develop an understanding of what such self-knowledge means for effective communication and good relationships with patients and caregivers'. ${ }^{73}$ Potential themes include: a reflection on the nature of science using a philosophy of science approach; the differences between the goals of clinical medicine and the basic sciences; the nature of clinical rationality and analyses of central concepts of clinical medicine, including 'patient', 'disease' and 'therapy'. ${ }^{67}$ The rationale is that health sciences educators who have learnt about these issues and reflected on and adjusted their own practices, will impart this knowledge and demonstrate its enactment to the students that they teach in classrooms and at bedsides.

\section{Cultivating a social ethic}

The third critical orientation is the cultivation of a social ethic and a sophisticated understanding of political economy and the structural determinants of health. By a social ethic, we refer to an attentiveness to history, social context and social justice in the practice of medicine and healthcare, and an understanding of oneself as an actor with values-informed by historical and sociopolitical factors-that shape clinical interactions. South Africa has a rich set of histories related to the development of the primary healthcare model spearheaded by Sidney and Emily Kark in the $1940 \mathrm{~s}^{7475}$; the role of healthcare professionals in the anti-apartheid movement and in social justice action such as in the fight for access to antiretroviral therapy. Despite this valuable archive, health sciences curricula are stubbornly ahistorical. Apart from including such content for its educational value, integrating an historical and contemporary awareness 
is essential to fostering the critical lens required for practising in postapartheid South Africa. Again, this is less about adding courses on history or political economy, and more about training health professionals to be sensitive to the social context in which their practice is embedded and to be advocates for social justice.

In his 1985 piece on Struggles for Control: The Social Roots of Health and Healing in Modern Africa, Feierman argued that: 'The person who controls therapy serves as a conduit transmitting general social values, but is also capable of reshaping and reinterpreting those values in the healing process' ${ }^{76}$ In other words, the authority that training in the health professions affords brings with it a responsibility. As Feierman stated, "If you are a doctor in South Africa and do not choose to make alliances among the disenfranchised, how do you serve the whole of society ethically?" This statement is as relevant today. While it is necessary to be mindful of the origins of our own moral prescriptions as healthcare practitioners, we agree with Kleinman's sentiment that 'a moral sensibility of critical self-reflection' is an important orientation to inculcate in health sciences students. ${ }^{77}$ It is our contention that, in the South African context, such a moral sensibility must include a commitment to action that works to decrease health inequalities and inequities in access to care.

Honing such a sensibility will be no straightforward task. Higher education institutions are themselves fraught with the challenges of increasing access to poor and working-class students; diversifying a predominantly white academy; shifting hierarchies of knowledge production and changing university cultures with long histories. ${ }^{19}$ There is also a persistent gap between i) the intentions of programme planners (the espoused curriculum); ii) the learning and assessment opportunities that educators create for students (the enacted curriculum) and iii) the manner in which students engage in educational activities (the experienced curriculum). ${ }^{78}$ As past studies at South African universities have shown, there are real disjunctures between the values and expectations that students bring with them to the classroom, and the values of professionalism and public service espoused by curricula. ${ }^{79}{ }^{80}$ As Ssebunnya argues, 'moral enculturation occurs mainly in a distinctive "hidden curriculum" rather than in formal coursework'. The hidden curriculum 'connotes a distinctive value-laden medical morality that is transmissible through socialisation and role-modelling in the medical school moral ecosystem'. ${ }^{81}$ The hidden curriculum, by its very nature, cannot be formalised - it is 'a dynamic phenomenological reality rooted in the intangible moral behaviour exemplified by role models. ${ }^{82}$

How can we then ensure that faculty members are appropriate role models for students, especially when significant learning takes place in clinical spaces alongside clinicians who may or may not have had formal pedagogical training? Ssebunnya advocates for health sciences faculties to articulate a set of standards and practices that reflect their desired 'moral ecosystem', and to prioritise professional values in staff recruitment criteria. ${ }^{81}$ A starting point could be the subject position advocated for all educators in South Africa: the teacher as democratic citizen, who 'embraces the virtues of listening, talking, reaching consensus, disagreement and critical engagement, and simultaneously extends their responsibility towards society...a democratic teacher is a critical-reflective practitioner who seeks to cultivate social justice through pedagogical actions'..$^{82}$

In addition to the essential place of appropriate role-modelling, health sciences faculties can learn from other disciplines, notably philosophy, to realise this vision. As philosopher Lamola argues, a curriculum that prioritises social justice must speak to 'the lived-experiences and consequent hermeneutical universe of the poor and marginalised' in South Africa. ${ }^{83}$ If culture is 'the site of social justice' Lamola continues, then what requires transformation for philosophy is not its content, but the way that it is done: 'the way philosophy is done, will dictate its syllabus'. ${ }^{84}$ Lamola advocates for 'philosophy seeking its reflective-material from the actual experiences and aspirations of people, conscious a priori of the marginalised, premised on the quest for justice and the good life for all'.

Similarly, it is not primarily the content of health sciences curricula that requires transformation-an 'add-on' course on social justice or ethics will not suffice. Rather what is required is a critical orientation across curricula that cultivates a social ethic. Commenting on the 'conceptual bioethics lag in Africa', Ssebunnya advocates for dignity as a central conceptual focus of any health sciences training in Africa, suggesting that 'an introductory course on the dignity of the human person should become mandatory'. ${ }^{85}$ Rather than reserving this as an introductory course, we would argue for dignity as a core theme across curricula, and respect for human dignity as one of the key articulated standards of practice for health educators to uphold when modelling behaviour to students.

Finally, language is an important arena for social justice. As discussed earlier, English is the medium of instruction on most health sciences campuses. Luckett argues that

'[t]he widely unquestioned hegemony of colonial languages in institutions of civil society poses a linguistic and cultural barrier to those who grow up as subjects of political society without access to the habitats necessary for acquiring high levels of proficiency in the languages of power... They often experience a contradiction between the equity policy that admits them (a structural enablement) and the cultural and linguistic demands of the institution (a cultural constraint)-leading to their correction or elimination (academic exclusion)'. ${ }^{72}$

Luckett is wary of the development programmes many universities have adopted for 'underprepared' students. The silo-ed training of 'prepared' and 'underprepared' students (eg, who might have an extended course) may have merit, but may inadvertently marginalise students for whom English is not a first language. Luckett suggests the expansion of Education Development Programmes to include all students as one way of reforming curricula: typical courses could include diversity studies, African studies, community engagement and courses in African languages. ${ }^{72}$ Again, rather than addition, the challenge is integration, and like Ssebunnya, Luckett recognises that staff development will be key. While a new generation of black scientists and clinicians are leading important changes in the academy and acting as role models, ${ }^{86}$ faculties will need to continually foreground social justice and a social ethic for the training of the next generation of health scientists.

\section{Embedding relatedness in practice}

The fourth critical orientation is a focus on relatedness, or valuing relationships and valuing experience. Higher education for the public good should be framed by concepts including ethics, care, hope and humanity. ${ }^{14}$ The practice of medicine relies constitutively on hands-on knowledge, experience and expertise; and the delicate relationship between clinician and healer, curing and healing. Symbols and the structuring of narrative are important to the clinical encounter, and the contexts and histories of lived experience matter crucially to the ways in which 'health' is constituted and lived. As philosopher and physician Canguilhem has argued, the organism and its milieu establish their own 'norm' in constituting the envelope in which 
we can talk sensibly of 'health'. ${ }^{87}$ 'Relationships' themselves are the primary material through which health and healing are made possible, and following anthropologist Strathern ${ }^{88}$ 'health' itself is better understood as constituted by relations and not by means of absolute measures, as mechanist conceptions of biology suggest.

Understanding the fundamental difference between curing and healing is a central part of this critical orientation. As Canguilhem put it, healing is fundamentally subjective while cure reflects forms of internal change adhering to external validation. ${ }^{87}$ In Meyers' formulation,

\begin{abstract}
'cure is the success of change within, verified statistically or otherwise from without...Cure is return whereas healing opens onto something new and previously unfamiliar or unknown. Healing does not restore a previously existing order; it does not return to an old norm... healing is a process of establishing new norms in and of the body'. ${ }^{89}$
\end{abstract}

How then should health professions training integrate this insight both into the science and clinical practice of medicine? How might health professions training imbue a stronger 'logic of care ${ }^{190}$ in trainee clinicians? As Mol explains, 'for the logic of care, gathering knowledge is not a matter of providing better maps of reality, but of crafting more bearable ways of living with or in reality'. ${ }^{90}$

The social sciences have much to offer in the way of thinking about how this critical orientation might be integrated into health sciences training. Anthropological insights into diverse healing modalities, and concepts of body and health found around the world have long been mobilised as counter-examples to biomedicine's mechanistic rationality and appeals to science for authority. For example, an important contribution from anthropology has been to show the fundamental importance of symbols and narratives for structuring experiences of healing or curing in all healing systems including biomedicine. ${ }^{91}{ }^{92}$ In the southern African context, Manderson and Block show that a range of practices of relatedness shapes the organisation of affection and thus the relations of care between people. They show how caring for and caring about are entangled modes of acting/feeling. ${ }^{93}$ Livingston's descriptions of doctors and nurses making do in a cancer ward in Botswana shows patients and their families being drawn into forms of mutual care that complicates the divisions between doctor, nurse, patient and relative. ${ }^{94}$ Similarly, Nyamebedha and Aagaard-Hansen describe the Luo concept of $d u o l$ as a symbol and social system embodying unity and social solidarity that might mitigate the losses caused by HIV in western Kenya. ${ }^{95}$ Drawing on Carsten's notion of relatedness, ${ }^{96}$ they suggest that $d u o l$ reflects something of the new social forms, institutional ties and community responses to HIV in which new relations of care are nurtured by reference to local idioms of mutual aid. Klaits' ethnography of the healing power of caring and intimacy in a small Apostolic church in Botswana is equally compelling in its attention to ordinary practices of care around HIV. ${ }^{97}$ Ethnographic attention to the importance of feeling and practice in these Southern contexts thus points to non-biomedical concepts and techniques that respond to and are entwined with institutions and techniques of biomedicine and global health.

Kleinman's path-breaking insight into the importance of narrative for understanding the experience of illness, and folding that understanding back into biomedical treatment, remains relevant. ${ }^{98}$ Narrative as a technique and a theory of illness ${ }^{98} 99$ establishes the grounds for bringing together evidence and experience, reaffirming social concerns with identity and political concerns with equity, in ways that exceed formal instruction in scientific method. Diab et al at the University of KwaZulu-Natal provide a useful example of how the importance of relatedness can be embedded in pedagogy. ${ }^{100}$ They argue that first-person narratives of real clinical interactions are more pedagogically effective than using fictionalised 'typical' cases when teaching. Collaborative engagement with educators' personal narratives in peer meetings is one way for educators to reflect on the social, political, moral or ethical learning points that can be developed from each narrative. A clinical teacher who offers her personal perspective and experience to a problem lends credibility to the concerns and dilemmas that the situation poses. Sharing rich and complex narratives with students can illustrate the thick social relations that scaffold clinical encounters. Rather than stripping away complexity to facilitate learning, offering students real-world narratives that do not obscure complexity teaches students about uncertainty, competing concerns, and real-world 'messiness', and encourages respect and curiosity in clinical interactions. ${ }^{100}$

\section{CONCLUSION}

In this paper, we have offered a set of critical orientations and an integrated framework for humanising and decolonising health sciences pedagogy. Educators, students and patients alike are calling for transformation. To achieve this goal, we argue that knowledge and ways of knowing from the human and social sciences need to be integrated into health professions curricula, rather than merely added onto teaching and learning programmes dominated by biomedical science. Experience, especially from the global North, has taught us that the mere addition of humanities-inspired courses often fall far short of the goal of transforming health sciences education in ways that will cultivate more humanised professionals.

We have proposed four elements of an integrated approach for humanised and decolonised health sciences pedagogy. First, recognising the value of qualitative research, lived-experiential knowledge and the Southern canon is essential for creating an institutional culture that celebrates local forms of knowledge and prioritises the inclusion and access of students historically excluded from health sciences education. This is also essential for producing health professionals who can think critically about knowledge production and how to deliver equitable and effective healthcare. Second, health professionals should be trained to reflect on their professional identity and values, recognising that respectful patient interaction is a core component of clinical competence and good quality healthcare, and not merely optional 'good bedside manners'. ${ }^{101}$ Third, a critical orientation that aims to cultivate a social ethic is imperative for producing health professionals who can recognise the historical contexts of colonialism and the inheritance of racial logics of exclusion that perpetuate structural violence and shape the contexts in which they learn and practice. Finally, healthcare without the care component is greatly impoverished, and a critical pedagogical orientation that privileges the importance of relatedness and caregiving is crucial to producing practitioners who work towards alleviating individual and social suffering. ${ }^{4}$

The deeply complex, context-dependent and relational nature of health, disease and healing necessitates that healthcare providers have insights, skills and knowledge from the humanities and social sciences as integral parts of their professional capabilities. To be sure, reforming curricula in this way will be no mean feat: it will entail intervention at multiple levels, the careful retraining and reframing for the current generation of 
healthcare practitioners who mentor and teach health sciences students and innovative ways to teach and also assess these critical orientations, given what we know about assessment-driven learning. ${ }^{102}$ And yet to shy away from making these important shifts in practice and pedagogy would be to fail patients and future practitioners alike.

Acknowledgements We acknowledge Christopher Colvin and Hayley MacGregor and the 2015 Critical Health Social Sciences workshop; attendees at the 2016 Brocher Foundation workshop on Humanising the Health Sciences; fellow interest group members Lizahn Cloete, Ferdinand Mukumbang and Guddi Singh; and the Medical Health Humanities Africa Network. We thank the editors of this Special Issue Carla Tsampiras and Nolwazi Mkhwanazi, and the anonymous reviwers for their useful feedback.

Contributors The authors planned and conceptualised the piece together. MP created a framework and the authors contributed equally to writing and revisions. MP edited the piece for cohesion and attended to technical aspects such as referencing. All authors contributed to revisions based on reviewers' comments and read, commented on and approved the entire manuscript before the final submission.

Funding The authors are grateful for open access funding from Stellenbosch University, South Africa; BG acknowledges support from a Stellenbosch University Teaching Fellowship. The authors acknowledge generous funding from the Brocher Foundation, Switzerland. The Brocher Foundation mission is to encourage research on the ethical, legal and social implications of new medical technologies. Its main activities are to host visiting researchers and to organise symposia, workshops and summer academies. More information on the Brocher foundation programme is available at www.brocher.ch.

\section{Competing interests None declared.}

Patient consent Not required.

Provenance and peer review Not commissioned; externally peer reviewed.

Open access This is an open access article distributed in accordance with the Creative Commons Attribution Non Commercial (CC BY-NC 4.0) license, which permits others to distribute, remix, adapt, build upon this work non-commercially, and license their derivative works on different terms, provided the original work is properly cited, appropriate credit is given, any changes made indicated, and the use is non-commercial. See: http://creativecommons.org/licenses/by-nc/4.0/.

\section{REFERENCES}

1 Stern DT, Cohen JJ, Bruder A, et al. Teaching humanism. Perspect Biol Med 2008;51:495-507.

2 Gordon D. Tenacious assumptions in western medicine. In: Lock M, Gordon D, eds. Biomedicine examined. Dordrecht: Kluwer, 1988:19-55.

3 Marcum JA. Reflections on humanizing biomedicine. Perspect Bio/ Med 2008;51:392-405.

4 Kleinman A, Hanna B. Catastrophe, Caregiving and Today's Biomedicine. Biosocieties 2008;3:287-301.

5 Archer E, Bezuidenhout J, Kidd M, et al. Making use of an existing questionnaire to measure patient-centred attitudes in undergraduate medical students: a case study. Afr J Health Prof Educ 2004;6:150-4.

6 Archer E, van Heerden BB. Undergraduate medical students' attitudes towards patient-centredness: a longitudinal study. MedEdPublish 2017;6:47.

7 Heath I. How medicine has exploited rationality at the expense of humanity. BMJ 2016;355:15705.

8 Coovadia H, Jewkes R, Barron P, et al. The health and health system of South Africa: historical roots of current public health challenges. Lancet 2009;374:817-34.

9 Mudimbé VY. The invention of Africa: gnosis, philosophy, and the order of knowledge. London: Currey Press, 1988.

10 Mbembe AJ. On the postcolony. Berkeley: University of California Press, 2001.

11 Mbembe AJ. Critique of black reason. trans. Laurent Dubois. Johannesburg: Wits University Press, 2017.

12 , Mbembe AJ. Decolonizing the university: New directions. Arts and Humanities in Higher Education 2016;15:29-45.

13 wa Thiong'o N. Decolonising the mind: the politics of language in African Literature. London: James Currey, 1986.

14 Leibowitz B. Higher education for the public good: views from the South. London: Institute of Education Press, 2013.

15 Meyers T, Hunt NR. The other global South. Lancet 2014;384:1921-2.

16 Subreenduth S. Disrupting mainstream discourse in teaching education through decolonising pedagogies. In: Leibowitz B, ed. Higher education for the public good: views from the South. London: Institute of Education Press, 2013.
17 Montgomery K. How doctors think: clinical judgment and the practice of medicine. Oxford University Press: Oxford, 2006.

18 Shapiro J, Coulehan J, Wear D, et al. Medical humanities and their discontents: definitions, critiques, and implications. Academic Medicine 2009;84:192-8.

19 Badat S. Theorising institutional change: post-1994 South African higher education. Studies in Higher Education 2009;34:455-67.

20 Abdool Karim SS. Medical education after the first decade of democracy in South Africa. Lancet 2004;363:1395.

21 Mayosi BM, Benatar SR. Health and health care in South Africa--20 years after Mandela. N Engl J Med 2014;371:1344-53.

22 Von Holdt K, Murphy M. et al Public hospitals in South Africa: Stressed institutions, disempowered management. In: Buhlungu S, Daniel J, Southall R, Lutchman J, . eds. State of the Nation: South Africa. Cape Town: HSRC Press, 2007:312-41.

23 Seggie JL. MBChB curriculum modernisation in South Africa - growing doctors for Africa.'. AJHPE 2010;2:8-14.

24 Boelen C. 'The five-star doctor. an asset to health care reform?'. Geneva: World Health Organisation, 1993.

25 Mash R, Malan Z, von Pressentin K, et al. Strengthening primary health care through primary care doctors: the design of a new national postgraduate diploma in family medicine. S Afr Fam Pract 2015;6190:1-5.

26 Bowden J, Hart G, King B, et al. Generic capabilities of ATN university graduates. $2000 \mathrm{http}: / w w w . c l t . u t s . e d u . a u / A T N$.grad.cap.project.index.html

27 Hartman N, Kathard H, Perez G, et al. Health sciences undergraduate education at UCT: a story of transformation. S Afr Med J 2012;102:477-80.

28 Reid S. The 'medical humanities' in health sciences education in South Africa. S Afr Med J 2014;104:109-10.

29 Langa M. \#Hashtag: an analysis of the \#FeesMustFall Movement at South African universities. Johannesburg: Centre for Violence and Reconciliation, 2017.

30 Behari-Leak K, Ramugondo E, Kathard H. Students in South Africa feel unheard. Here's one way to listen, The Conversation. 2016 https://theconversation.com/ students-in-south-africa-feel-unheard-heres-one-way-to-listen-66805.

31 Delvecchio-Good M. American medicine: the quest for competence. Berkeley: University of California Press, 1995.

32 Swartz L. The virtues of feeling culturally incompetent. Monash Bioeth Rev 2007;26:36-46.

33 Napier AD, Ancarno C, Butler B, et al. Culture and health. The Lancet 2014;384:1607-39.

34 Taylor JS. The story catches you and you fall down: tragedy, ethnography, and "cultural competence". Med Anthropol Q 2003;17:159-81.

35 Metzl JM, Hansen H. Structural competency: theorizing a new medical engagement with stigma and inequality. Soc Sci Med 2014;103:126-33.

36 Freire P. Education for critical consciousness. London: Sheed and Ward, 1974.

37 Heleta S. Decolonisation of higher education: Dismantling epistemic violence and Eurocentrism in South Africa. Transformation in Higher Education 2016;1:a9.

38 Wingfield B. What decolonised education should and shouldn't mean. The Conversation. 2017 https://theconversation.com/what-decolonised- educationshould-and-shouldnt-mean72597 (accessed 15 Aug 2017).

39 Fomunyam KG. Decolonising the engineering curriculum in a South African University of Technology. IJAER 2018;12:6797-805.

40 Knight J. Decolonizing and transforming the Geography undergraduate curriculum in South Africa. S Afr Geogr J 2018;4:1-20.

41 Pillay SR. Cracking the fortress: can we really decolonize psychology? S Afr J Psychol 2017; $47: 135-40$.

42 Fanon F. The wretched of the earth. Harmondsworth: Penguin, 1967.

43 Biko S. I write what I like. Selected writings. Chicago: University of Chicago Press, 2015.

44 Dewachi 0 . Teaching at the margins: experiences of anthropology and medicine in a middle-eastern setting. Alterities 2009;2:129-35.

45 OCEBM Levels of Evidence Working Group. The Oxford 2011 Levels of Evidence. Oxford Centre for Evidence-Based Medicine. http://www.cebm.net/index.aspx?o= 5653.

46 Wainwright M, Macnaughton J. Is a qualitative perspective missing from COPD guidelines? Lancet Respir Med 2013;1:441-2.

47 Pillay M, Kathard H. Decolonizing health professionals' education: audiology and speech therapy in South Africa. African Journal of Rhetoric 2015;7:193-227.

48 Kaminer D, Eagle G, Crawford-Browne S. Continuous traumatic stress as a mental and physical health challenge: Case studies from South Africa.J Health Psychol 2018;23:1-12.

49 Daniels K, Loewenson R, George A, et al. Fair publication of qualitative research in health systems: a call by health policy and systems researchers. Int J Equity Health 2016;15:98.

50 Daniels K, Hanefeld J, Marchal B. Social sciences: vital to improving our understanding of health equity, policy and systems. Int J Equity Health 2017;16:57.

51 Chilisa B. Decolonising transdisciplinary research approaches: an African perspective for enhancing knowledge integration in sustainability science. Sustainability Science 2017;12:813-27. 
52 Glenton C, Lewin S, Norris SL. Using evidence from qualitative research to develop WHO guidelines. WHO handbook for guideline development. 2nd edn, 2014:183-200.

53 Glenton C, Colvin CJ, Carlsen B, et al. 'Barriers and facilitators to the implementation of lay health worker programmes to improve access to maternal and child health: qualitative evidence synthesis'. Cochrane Database Syst Rev 2013;10:CD010414.

54 Lewin S, Glenton C, Munthe-Kaas H, et al. Using qualitative evidence in decision making for health and social interventions: an approach to assess confidence in findings from qualitative evidence syntheses (GRADE-CERQual). PLOS Med 2015;12:e1001895.

55 Colvin CJ. Anthropologies in and of evidence making in global health research and policy. Med Anthropol 2015;34:99-105.

56 Chambers LA, Jackson R, Worthington C, et al. Decolonizing scoping review methodologies for literature with, for, and by indigenous peoples and the african diaspora: dialoguing with the tensions. Qual Health Res 2018;28:175-88.

57 Aina OF. Mental illness and cultural issues in West African films: implications for orthodox psychiatric practice. Med Humanit 2004;30:23-6.

58 Swartz L. Race, gender and the impossibilities of care. Med Humanit 2012;38:34-7.

59 Eisenberg L, Kleinman A. The relevance of social science for medicine. London: Reidel, 1981.

60 Good MJ, Delvecchio-Good M. The biotechnical embrace. Cult Med Psychiatry 2001;25:395-410

61 Sharples JM, Oxman AD, Mahtani KR, et al. Critical thinking in healthcare and education. BMJ 2017;357:j2234

62 Macnaughton J. The humanities in medical education: context, outcomes and structures. Med Humanit 2000;26:23-30.

63 Shapiro J, Coulehan J, Wear D, et al. Medical humanities and their discontents: definitions, critiques, and implications. Acad Med 2009;84:192-8.

64 Latour B, Woolgar S. Laboratory life: the construction of scientific facts. Princeton University Press: Princeton, NJ, 1986.

65 Berg M, Akrich M. Introduction - bodies on trial: performances and politics in medicine and biology. Body Soc 2004:10:1-12.

66 Simon JR. Advertisement for the ontology for medicine. Theor Med Bioeth 2010;31:333-46.

67 Kriel J. Mind, matter and medicine. Transforming the clinical method. Amsterdam: Rodopi, 2000.

68 Gatens-Robinson E. Clinical judgment and the rationality of the human sciences. J Med Philos 1986;11:167-78.

69 Waymack MH. Yearning for certainty and the critique of medicine as "science". Theor Med Bioeth 2009;30:215-29.

70 Gerber B. Should we use philosophy to teach clinical communication skills? Afr J Prim Health Care Fam Med 2016;8:1292.

71 Penn C, Watermeyer J. Communication across cultures and languages in the health care setting: voices of care. London: Palgrave Macmillan, 2018.

72 Luckett K. Curriculum contestation in a post-colonial context: a view from the South. Teaching in Higher Education 2016;21:415-28.

73 Eley DS, Stallman H. Where does medical education stand in nurturing the 3 Rs in medical students: responsibility, resilience and resolve? Med Teach 2014;36:835-7.

74 Yach D, Tollman SM. Public health initiatives in South Africa in the 1940s and 1950s: lessons for a post-apartheid era. Am J Public Health 1993;83:1043-50.

75 Marks S. South Africa's early experiment in social medicine: its pioneers and politics. Am J Public Health 1997;87:452-9.

76 Feierman S. Struggles for control: the social roots of health and healing in modern Africa. Afr Stud Rev 1985;28:73-147.

77 Kleinman A. The divided self, hidden values, and moral sensibility in medicine. The Lancet 2011;377:804-5.
78 Wald HS, Anthony D, Hutchinson TA, et al. Professional identity formation in medical education for humanistic, resilient physicians: pedagogic strategies for bridging theory to practice. Acad Med 2015;90:753-60.

79 Van Rooyen M. The views of Medical Students on professionalism in South Africa. South African Family Practice 2004;46:28-31.

80 Draper C, Louw G. What is medicine and what is a doctor? Medical students' perceptions and expectations of their academic and professional career. Med Teach 2007;29:e100-e107.

81 Ssebunnya GM. Beyond the hidden curriculum: the challenging search for authentic values in medical ethics education. S Afr J Bioeth Law 2013;6:48.

82 Waghid Y. Hopeful teacher education in SA: towards a politics of humanity. Leibowitz B, ed. Higher education for the public good: views from the South. London: Institute of Education Press, 2013.

83 Lamola MJ. On a contextual South African philosophy curriculum: towards an option for the excluded. South African Journal of Philosophy 2016;35:501-12.

84 Jones W. 'The future of philosophy in South Africa.' unpublished paper, wild coast philosophy symposium: Cintsha, 2012.

85 Ssebunnya GM. Beyond the sterility of a distinct african bioethics: addressing the conceptual bioethics lag in Africa. Dev World Bioeth 2017;17:22-31.

86 Nordling L. South African science faces its future. Nature 2018;554:159-62.

87 Canguilhem G. Is a pedagogy of healing possible? trans. Steven Miller. Umbr(a):Incurable 2006;1:9-21.

88 Strathern M. The relation: issues in complexity and scale. Cambridge: Prickly Pear Press, 1995

89 Meyers T. The clinic and elsewhere: addiction, adolescents, and the afterlife of therapy. Washington: Washington University Press, 2013.

$90 \mathrm{Mol}$ A. The logic of care: health and the problem of patient choice. New York: Routledge, 2008.

91 Feierman S, Janzen JM. The social basis of health and healing in Africa. Berkeley: University of California Press, 1992.

92 Levine S. Medicine and the politics of knowledge. Cape Town: HSRC Press, 2012.

93 Manderson L, Block E. Relatedness and care in Southern Africa and beyond. Soc Dyn 2016;42:205-17

94 Livingston J. Improvising medicine: an African oncology ward in an emerging cancer epidemic. Durham: Duke University Press, 2012.

95 Nyambedha EO, Aagaard-Hansen J. Practices of relatedness and the re-invention of duol as a network of care for orphans and widows in Western Kenya. Africa 2007;77:517-34

96 Carsten J. Cultures of relatedness: new approaches to the study of kinship. Cambridge: Cambridge University Press, 2000.

97 Klaits F. Death in a church of life: moral passion during Botswana's Time of AIDS Berkeley: University of California Press, 2010.

98 Kleinman A. The illness narratives: suffering, healing and the human condition. New York: Basic Books, 1988.

99 Montgomery Hunter K. Doctors' stories: the narrative structure of medical knowledge. Princeton University Press: Princeton, 1991.

100 Diab P, Naidu T, Gaede B, et al. Cross-cultural medical education: Using narratives to reflect on experience. Afr J Health Prof Educ 2013;5:42-5.

101 Kurtz SM, Silverman J, Draper J. Teaching and learning communication skills in medicine. 2nd edn. Oxon: Radcliffe Publishing, 2005.

102 Burch V, Reid S. Fit for purpose? The appropriate education of health professionals in South Africa. S Afr Med J 2011;101:25-6.

103 Posel D. Race as common sense: racial classification in twentieth-century South Africa. Afr Stud Rev 2001;44:87-113. 